\title{
Magnetic resonance spectroscopic study of parkinsonism related to boxing
}

\author{
C A Davie, Z Pirtosek, G J Barker, D P E Kingsley, P H Miller, A J Lees
}

\begin{abstract}
Proton magnetic resonance spectroscopy, localised to the lentiform nucleus, was carried out in three ex-professional boxers who developed a parkinsonian syndrome, six patients with idiopathic Parkinson's disease, and six age matched controls. The three ex-boxers all showed a pronounced reduction in the absolute concentration of $\mathrm{N}$ - acetylaspartate compared with the patients with idiopathic Parkinson's disease and the control group. This reduction is likely to reflect neuronal loss occurring in the putamen and globus pallidus and supports the hypothesis that the extrapyramidal syndrome that may occur in ex-boxers is a distinct entity from idiopathic Parkinson's disease.
\end{abstract}

(F Neurol Neurosurg Psychiatry 1995;58:688-691)

Keywords: boxing; parkinsonism; magnetic resonance spectroscopy

The development of traumatic encephalopathy in boxers was first described in the medical literature when in 1928 Martland coined the term punch drunk to describe boxers who developed unsteadiness on their feet and who moved and thought more slowly. ${ }^{1}$ Since then, there have been clinical reports in which the picture of traumatic encephalopathy in boxers has been characterised by evidence of damage to one or more of the pyramidal, extrapyramidal, or cerebellar systems, with associated dementia, psychosis, and personality changes in some cases. ${ }^{2-5}$ The condition usually has an insidious onset and may present initially with affective disturbances and psychotic symptoms. The development of amnesia with the signs of parkinsonism may then follow. Finally, patients may develop generalised cognitive impairment. ${ }^{5}$ The clinical course may arrest during any of these stages and the severity of the syndrome correlates to a limited degree with the duration of the boxer's career $^{3}$ and the total number of bouts. ${ }^{6}$

The development of parkinsonism is a relatively common feature in those boxers developing the punch drunk syndrome. Roberts ${ }^{6}$ noted evidence of extrapyramidal involvement in 20 of the 52 cases of traumatic encephalopathy among retired professional boxers that he found in the medical literature. There are, however, few reports in which a parkinsonian syndrome develops as the sole or predominant manifestation of boxing injuries ${ }^{349}$ raising the possibility that parkinsonism occurring in boxers may simply be due to coincidental idiopathic Parkinson's disease rather than from a direct consequence of head trauma. ${ }^{67}$

Postmortem studies in boxers with posttraumatic encephalopathy have shown distinct pathological changes. ${ }^{8-10}$ Corsellis et $a l^{, 9}$ in a study of 15 boxers, described the presence of neurofibrillary tangles spread diffusely through both the cerebral cortex and brainstem, cavum septi pellucidi, cerebellar and cerebral scarring, and degeneration of the substantia nigra. Lewy bodies were not a pathological feature. Although no amyloid plaques were described in this paper, a follow up study of these brains by Roberts et al ${ }^{10}$ showed diffuse deposition of $\beta$ protein raising the possibility that the condition is more akin to Alzheimer's disease than idiopathic Parkinson's disease. Although neuronal loss has been well documented in the substantia nigra (predominantly affecting lateral rather than medial areas) there is no information regarding the degree of cell loss in the striatum. The presence of a cavum septum pellucidum during life in these patients may be confirmed by imaging. Computed tomography has shown this abnormality in $18 \%$ of boxers compared with its presence in $5 \%$ of the general population. ${ }^{2}$

Proton magnetic resonance spectroscopy (MRS) is a non-invasive method that provides information about the chemical pathology of conditions affecting the CNS. The largest peak visible with MRS is derived principally from $\mathrm{N}$-acetylaspartate (NAA), and amino acid contained almost exclusively within neurons and their processes in adult brain. ${ }^{11}$ Recent work from our group has shown that MRS centred in the lentiform nucleus may be useful in differentiating idiopathic Parkinson's disease from multiple system atrophy, ${ }^{12}$ a condition with which it may be confused clinically. ${ }^{1314}$ We now describe the clinical and MRS findings in three ex-professional boxers who developed a parkinsonian syndrome.

\section{Patients and methods \\ CASE HISTORIES}

Case 1

This patient was first described in the medical literature by Harvey and Newsom Davis in $1974 .{ }^{4} \mathrm{He}$ is a 45 year old man who was noted by his family to have slurring of speech after 
Boxing and MRs data

\begin{tabular}{lllllllll}
\hline Case No & Age & $\begin{array}{l}\text { Began } \\
\text { boxing }\end{array}$ & $\begin{array}{l}\text { Finished } \\
\text { boxing }\end{array}$ & $\begin{array}{l}\text { Amateur } \\
\text { bouts }\end{array}$ & $\begin{array}{l}\text { Professional } \\
\text { bouts }\end{array}$ & Knocked out & $\begin{array}{l}\text { Lentiform } \\
{[N A A]}\end{array}$ & $\begin{array}{l}\text { Fenestrated } \\
\text { septum pellucidum }\end{array}$ \\
\hline 1 & 45 & 14 & 24 & 75 & 25 & 1 & $6 \cdot 1 \mathrm{mmol} / 1$ & Present \\
2 & 52 & 15 & 27 & 1 & 24 & 3 & $7 \cdot 7 \mathrm{mmol} / 1$ & Absent \\
3 & 69 & 20 & 25 & $?$ & $30-40$ & 0 & $5 \cdot 14 \mathrm{mmol} / 1$ & Absent \\
\hline
\end{tabular}

Control medium [NAA] $9.94 \mathrm{mmol} / \mathrm{l}$; idiopathic Parkinson's disease, median [NAA] $9.99 \mathrm{mmol} / \mathrm{l}$.

being involved in 16 professional bouts (see table for boxing histories). The patient attributed his symptoms to a head injury he had received while in police custody. He did not lose consciousness during this alleged assault. Six months later he started to shuffle when walking and his legs appeared stiff. During his last few bouts he was aware of slowness on his feet and difficulty avoiding trouble in the ring. After retiring, his gait deteriorated; he developed lability of mood and became aggressive. When seen in 1974, he was noted to be cooperative but mentally slow. He had a symmetric extrapyramidal disorder with an expressionless face, generalised poverty of movements, cogwheel rigidity in all four limbs, and an extrapyramidal gait. Tendon reflexes were brisk, with a left extensor plantar. Treatment with a levodopa preparation at that time resulted in some improvement in his gait.

Before his current neurological assessment he had undergone treatment with lithium for a bipolar depressive disorder. On examination he was easily distractable and poorly cooperative. He had reduced facial expression. There was no rest tremor of his limbs and he displayed reduced arm swing on walking. There was bradykinesia and cogwheel rigidity that was worse on the left side. Power was normal. Reflexes were brisk but symmetric with flexor

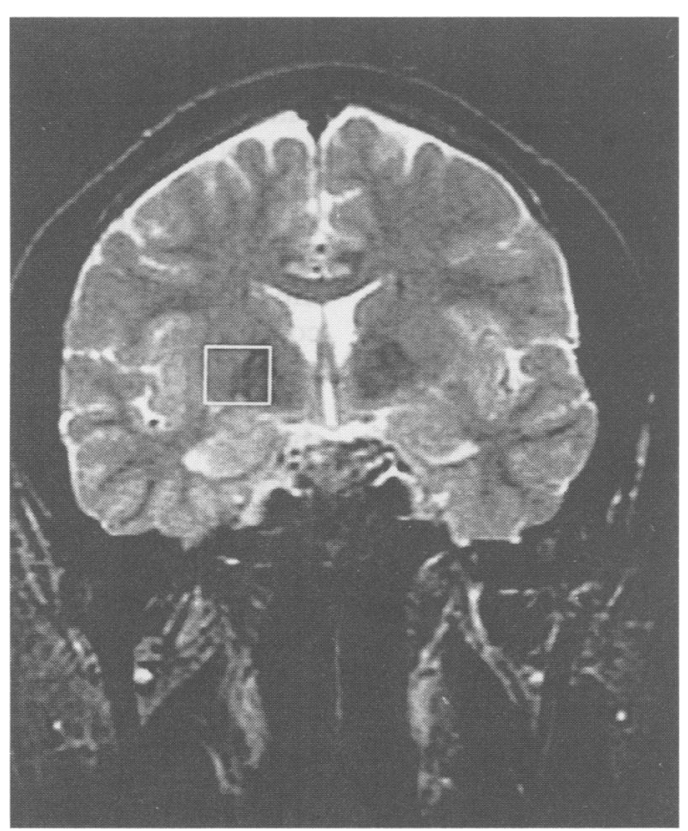

Figure 1 T2 weighted spin echo (TR 2000 ms TE $80 \mathrm{~ms}$ ) image from a healthy control showing a spectroscopic volume of interest centred on the right putamen and globus pallidus. plantar responses. There were no cerebellar signs, no sensory deficit, and sphincter function was normal.

\section{Case 2}

This $\mathbf{5 2}$ year old man fought professionally as a middle and cruiser weight (table). $\mathrm{He}$ was involved in a car accident when 28 and received a head injury for which he required 24 stitches. He did not lose consciousness during this event but his injuries were severe enough to prevent him continuing with his boxing career. At the age of 50 he began to drag his left leg and had trouble with his balance. He began to slow down. His speech became slurred and his memory deteriorated. There was slight improvement in his symptoms with levodopa treatment. On examination he had mild bradykinesia, with some cogwheel rigidity and pronounced blepharospasm. He had some slowness of gait with reduced arm swing. There were no cerebellar signs and no sphincter disturbance.

\section{Case 3}

This 69 year old man first began boxing at the age of 20 when he entered the navy. He boxed for about 18 months before turning professional. He denied being knocked out in any of his amateur or professional bouts (table). At the age of 66 he developed rest tremor of the right arm that soon spread to the other side. Levodopa produced only mild improvement. On examination he was moderately rigid and bradykinetic with bilateral rest tremor. Posture was stooped and he shuffled with short steps. Postural reflexes were impaired. There were no other neurological signs.

We also studied six patients aged 49 to 72 (median 56) years and median duration of disease of seven years with classic, levodopa responsive asymmetric idiopathic Parkinson's disease and six healthy controls with a median age of 59 years.

The study was approved by the joint ethics committee at the Institute of Neurology and the National Hospital for Neurology and Neurosurgery, London. Informed consent was obtained before each study. Magnetic resonance imaging and MRS were performed on a 1.5 Tesla GE whole body imager with a standard quadrature head coil. The study commenced with a coronal, T2 weighted, spin echo imaging sequence (TR $2000 \mathrm{~ms}$ TE $80 \mathrm{~ms}$ ) ( $3 \mathrm{~mm}$ slices with $1 \mathrm{~mm}$ gap, $256 \times 256$ matrix, echo train length 8 ).

Water suppressed spectra were obtained from volumes of interest $(3.4 \mathrm{ml}$ to $6 \mathrm{ml})$ centred on the putamen and globus pallidus 
(lentiform nucleus) using a STEAM sequence $^{15}$ (fig 1). In the boxers and idiopathic Parkinson's disease group, the basal ganglia contralateral to the most clinically affected side was studied. Acquisition parameters were TR $2270 \mathrm{~ms}$, TE $270 \mathrm{~ms}$, and TM $12 \mathrm{~ms}$. Data processing included $2 \mathrm{~Hz}$ line broadening, Fourier transformation, and zero order phase correction. Absolute concentrations for the metabolites were calculated with the fully relaxed water signal as an internal standard of reference. ${ }^{16}$ Metabolite concentrations [met] were calculated from the equation:

$$
\begin{aligned}
& \text { Met }=\left[\mathrm{H}_{2} \mathrm{O}\right] \times \mathrm{PI} \times \mathrm{T} 1_{\text {corr }} \times \\
& \mathrm{T} 2{ }_{\text {corr }} \times \mathrm{S}_{0 \text { Met }} / \mathrm{S}_{0 \mathrm{H}_{2} \mathrm{O}} \times 1 / 2^{\mathrm{R}}
\end{aligned}
$$

where $\mathrm{S}_{0 \text { Met }}$ and $\mathrm{S}_{\mathrm{H}_{2} \mathrm{O}}$ denote the signal intensities for metabolites and water respectively, $\left[\mathrm{H}_{2} \mathrm{O}\right]$ is the brain water concentration in grey matter taken as $47.2 \mathrm{M}, \mathrm{T} 1_{\text {corr }}$ and $\mathrm{T} 22_{\text {corr }}$ are $\mathrm{T} 1$ and $\mathrm{T} 2$ correction values based on published values for the metabolites studied, ${ }^{17}$ PI is the proton index, and $R$ (attenuation value) $=\left((\mathbf{R} 1+R 2){ }_{\text {metabolite }}-\right.$ (R1 + R2) water).

Statistical analysis was performed with a Mann-Whitney confidence interval and test. Results are expressed as a median value together with the range and $P$ value.

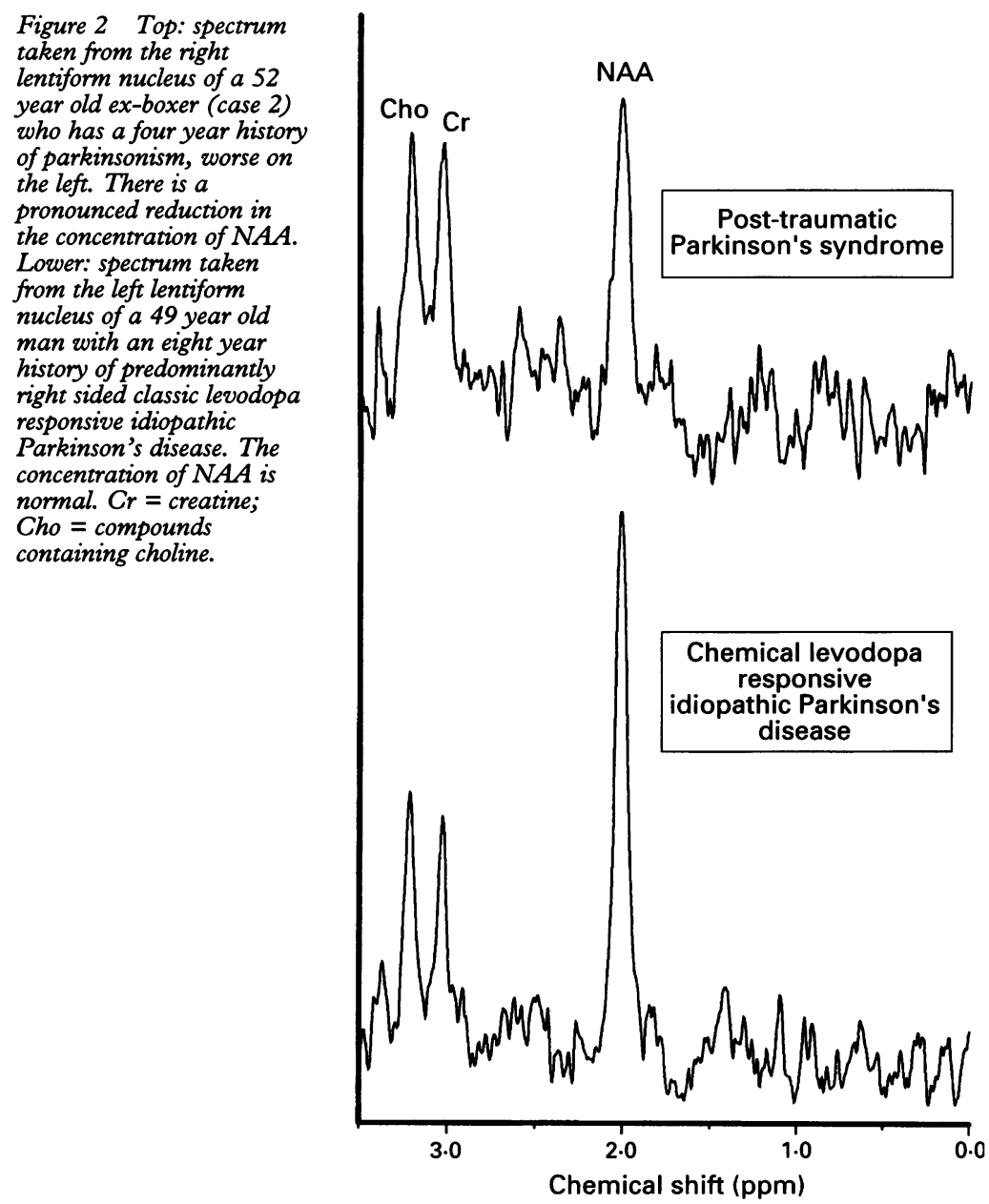

\section{Results}

MAGNETIC RESONANCE IMAGING

The three boxers all showed abnormalities on MRI. These consisted of discrete periventricular or subcortical white matter high signal lesions. There were no high signal lesions present in the basal ganglia. In one of the three boxers (case 1), there was evidence of cavum septi pellucidi. In three of the patients with idiopathic Parkinson's disease there were small periventricular or subcortical white matter lesions present on T2 weighted MRI. Similar changes were seen in two of the six controls. There was no evidence of cavum septi pellucidi in any of the patients with idiopathic Parkinson's disease or controls. In two of the patients with idiopathic Parkinson's disease there was a moderate degree of low signal extending from the globus pallidus into the medial border of the putamen. This was not present in the controls or in the three ex-boxers.

\section{MAGNETIC RESONANCE SPECTROSCOPY}

The table shows the concentrations of NAA from the lentiform nucleus in the three exboxers. These were all significantly lower (median $6.1 \mathrm{mmol} / \mathrm{l}$ ) than the NAA concentrations from the age matched controls (median 9.94 (range 9.26-10.77) $\mathrm{mmol} / \mathrm{l}, \mathrm{P}<$ 0.03 ) (fig 2). By contrast, there was no significant difference in the concentration of NAA in the idiopathic Parkinson's disease group (median 9.99 (range 9.0-11.0) $\mathrm{mmol} / \mathrm{l}, \mathrm{P}>$ $0.9)$ compared with the controls. There was no significant difference in the concentrations of creatine or compounds containing choline between the three groups.

\section{Discussion}

The most striking finding in this study was the significant reduction in the concentration of NAA from the putamen and globus pallidus in the ex-professional boxers with a parkinsonian syndrome, compared with the patients with idiopathic Parkinson's disease and the control group.

In adult brain, NAA is almost exclusively confined to neurons and their processes. ${ }^{11}$ An absolute reduction in NAA or a reduction in the NAA/creatine ratio has been seen in many conditions in which there is neuronal or axonal loss ${ }^{18-22}$ although in some disorders this abnormality may partly reverse, suggesting that neuronal dysfunction alone may contribute to a reduced ratio. ${ }^{23} 24$

There is, to our knowledge, no information in the medical literature describing the corpus striatum in patients with post-traumatic encephalopathy and, in particular, whether there is neuronal loss in this region of the brain. The reduction of NAA that we have shown in this small group of patients with parkinsonism related to a history of professional boxing suggests that neuronal loss may occur in the putamen, globus pallidus, or both in these patients, presumably secondary to head trauma. This hypothesis is supported by the results of an earlier study in which we 
found a reduction of NAA from the lentiform nucleus in patients with the striatonigral and olivopontocerebellar variants of multiple system atrophy, a condition in which neuronal loss is known to occur in the putamen, and to a lesser extent, in the globus pallidus. ${ }^{25} 26$ Neuronal loss within the striatum is not a feature of idiopathic Parkinson's disease ${ }^{27}$ and this is in keeping with the finding in the present study of a normal median concentration of NAA in the patients with idiopathic Parkinson's disease compared with the controls. The reduced concentration of NAA in the post-traumatic patients suggests that the extrapyramidal syndrome which may occur in ex-boxers is an entity distinct from idiopathic Parkinson's disease.

Prospective studies in patients diagnosed as having idiopathic Parkinson's disease have shown that up to $24 \%$ of patients have an alternative diagnosis at postmortem. ${ }^{14}$ The conditions most often misdiagnosed include multiple system atrophy, Steele-Richardson syndrome, and vascular disease, although the pathological changes of post-traumatic encephalopathy have been found at postmortem in the brains of a few patients believed during life to have idiopathic Parkinson's disease (Parkinson's Disease Society Brain Bank, Institute of Neurology, unpublished observations). This finding suggests that trauma may play a part in the development of a parkinsonian syndrome in at least some patients diagnosed as having idiopathic Parkinson's disease. Our finding of a reduction of NAA in the lentiform nucleus in three ex-boxers supports this hypothesis.

Two of the boxers in this study (cases 2 and 3) developed parkinsonism several years after the end of their boxing career. We cannot exclude the possibility that these patients have developed coincidental idiopathic Parkinson's disease unrelated to their history of head trauma. There are two reasons, however, why this seems unlikely. Firstly, these patients have only ever shown a mild or unsustained therapeutic response to levodopa which is very unusual in idiopathic Parkinson's disease. Secondly, both have shown a reduction of NAA in the basal ganglia with MRS, a finding not typical of idiopathic Parkinson's disease. How then, could one explain the late development of parkinsonism in these two patients? If head injury from boxing does produce neuronal loss within the striatum, then the degree of cell loss may be an important factor in determining when symptoms develop. If pronounced, parkinsonian features may develop at, or shortly after, the time of injury, as perhaps in case 1 . With less severe cell loss, however, the threshold required to produce symptoms may not be reached. With aging, there may be further loss of neurons from the basal ganglia leading to the development of an extrapyramidal syndrome.

In conclusion, proton MRS centred on the lentiform nucleus has shown a reduction of NAA (a neuronal marker) in three ex-professional boxers who developed a parkinsonian syndrome. By contrast, a group of patients with idiopathic Parkinson's disease showed preserved concentrations of NAA compared with controls. This finding supports the hypothesis that the parkinsonian syndrome occurring in boxers may be a separate clinical entity from idiopathic Parkinson's disease.

We thank Professor C D Marsden and Dr N Quinn for kindly allowing permission to study patients under their care. The NMR Research Group is supported by a generous grant from the Multiple Sclerosis Society of Great Britain and Northern Ireland. We also acknowledge G E (Milwaukee) for providing spectroscopy software for data analysis.

1 Martland HS. Punch drunk. $F A M A$ 1928;91:1103-7. 2 Casson IR, Siegel O, Sham R, Campbell EA, Tarlau M, Didomenico $\mathrm{A}$. Brain damage in modern boxers. $\mathfrak{f} A M A$ 1984;251:2663-7.

3 Critchley $M$. Medical aspects of boxing, particularly from a neurological standpoint. $B M \mathcal{F}$ 1957;i:357-66.

4 Harvey PKP, Newsom Davis J. Traumatic encephalopathy in a young boxer. Lancet 1974; ii:928-9.

5 La Cava G. Boxer's encephalopathy. $\mathcal{F}$ Sports Med 1963;3: 87-92.

6 Roberts AH. Brain damage in boxers. A study of prevalence of traumatic encephalopathy among ex-professional boxers. London: Pitman Medical, 1969.

7 Factor SA, Weiner WJ. Prior history of head trauma in Parkinson's disease. Mov Disord 1991;6:225-9.

8 Neubürger KT, Sinton DW, Denst J. Cerebral atrophy associated with boxing. Archives of Neurology and Psychiatry 1959;81:403-8.

9 Corsellis JAN, Bruton CJ, Freeman-Browne D. The aftermath of boxing. Psychol Med 1973;3:270-303.

10 Roberts GW, Allsop D, Bruton C. The occult aftermath of boxing. $\mathcal{F}$ Neurol Neurosurg Psychiatry 1990;53:373-8.

11 Urenjak J, Williams SR, Gadian DG, Noble M. Proton nuclear magnetic resonance spectroscopy unambiguously identifies different neural cell types. $\mathcal{f}$ Neurosci 1993;13:981-9.

12 Davie CA, Wenning GK, Barker GJ, et al. MRS to differentiate multiple system atrophy from idiopathic Parkinson's disease [letter]. Lancet 1993;342:681-2.

13 Rajput AH, Rozdilsky B, Rajput A. Accuracy of clinical diagnosis in parkinsonism-a prospective study. Can 7 Neurol Sci 1991;18:275-8

14 Hughes AJ, Daniel SE, Kilford L, Lees AJ. Accuracy of clinical diagnosis of idiopathic Parkinson's disease: a clinicopathological study of 100 cases. $f$ Neurol Neurosurg Psychiatry 1992;55:181-4.

15 Frahm J, Michaelis T, Merboldt KD, et al. Improvements in localised proton NMR spectroscopy of human brain, water suppression, short echo times and human brain, water suppression, short echo
$\mathcal{I}$ Mag Reson 1990;90:464-73.

16 Christiansen $P$, Henriksen $O$, Stubgaard M, Gideon P, Larsson HBW. In vivo quantification of brain metabolites by ' $\mathrm{H}$-MRS using water as an internal standard. Magn Reson Imaging 1993;11:107-18.

17 Frahm J, Bruhn H, Gyngell ML, Merboldt KD, Hänicke W, Sauter R. Localised proton NMR spectroscopy in different regions of the human brain in vivo: relaxation times and concentrations of cerebral metabolites. Magn Reson Med 1989;11:47-63.

18 Birken DL, Oldendorf WH. N- acetyl-Aspartic acid: a literature review of a compound prominent in $1 \mathrm{H}$ NMR spectroscopic studies of brain. Neurosci Biobehav Rev 1989;13:23-31.

19 Matthews PM, Francis G, Antel J, Arnold DL. Proton magnetic resonance spectroscopy for metabolic characmagnetic resonance spectroscopy for metabolic characterisation of plaqu

20 Chong WK, Sweeney B, Wilkinson ID, et al. Proton spectroscopy of the brain in HIV infection: correlation with clinical, immunologic and MR imaging findings. Radiology 1993;188:119-24.

21 Gideon P, Henriksen O, Sperling B, et al. Early time course of $\mathbf{N}$ acetylaspartate, creatine and phosphocreatine, and compounds containing choline in the brain after acute stroke. A proton magnetic resonance spectroscopy study. Stroke 1992;23:1566-72.

22 Shino A, Matsuda M, Morikawa S, et al. Proton magnetic resonance spectroscopy with dementia. Surg Neurol 1993;39:143-7.

23 Arnold DL. Reversible reduction of N- acetylaspartate after acute central nervous system damage. In: Proceedings of the 11th annual meeting of the society for Proceedings of the 11th annual meeting of the society for magnetic resond

24 Davie CA, Hawkins CP, Barker GJ, et al. Serial proton magnetic resonance spectroscopy in acute multiple sclerosis lesions. Brain 1994;117:49-58.

25 Daniel SE. The neuropathology and neurochemistry of multiple system atrophy. In: Bannister R, Mathias C, eds. Autonomic failure. A textbook of clinical disorders of the autonomic nervous system. 3rd ed. Oxford: Oxford University Press, 1992:564-85.

26 Fearnley JM, Lees AJ. Striatonigral degeneration. A clinicopathological study. Brain 1990;113:1823-42.

27 Oppenheimer DR, Esiri MM. Diseases of the basal ganglia, cerebellum and motor neurons. In: Hume Adam J, Duchen LW, eds. Greenfield's neuropathology 5th London: Edward Arnold, 1992:988-97. 